\title{
Modeling Deficiency of Hemoglobin Severity Among Children in Ethiopia
}

\author{
Ayele Gebeyehu Chernet Teklu Nega Mohammed Derese Biru \\ Department of Statistics, College of Natural and Computational Sciences Wolkite University, Wolkite, Ethiopia
}

\begin{abstract}
Background: Anemia is a public health problem that affects populations worldwide. Anemia in children is a recognized public health problem that impacts adversely on child morbidity, mortality and impairs cognitive development. This study aimed to determine the prevalence of mild, moderate and severe anaemia, and the associated factors among children under-five years in EthiopiaMethod: The data was obtained from 2016 Ethiopia Demographic and Health Survey which is the fourth survey. The sample was selected using a stratified; two-stage cluster sampling design and the data was analyzed using Partial Proportional Odds model. Results: From 4684 sample of children half of the children (54\%) have moderate anemic status while $39.4 \%$ and $6.6 \%$ of them have mild and severe anemic status respectively. The highest prevalence of anemia among children observed in Somali (17.8\%) and the lowest percentage that was recorded in Addis Ababa (3.1\%). Conclusion: The female children, rural children, children from poor family, and having low weight are related to the severity of anemia.
\end{abstract}

Keywords: Anaemia, under five children, Partial proportional odds model, Ethiopia

DOI: $10.7176 / \mathrm{JHMN} / 68-01$

Publication date: November $30^{\text {th }} 2019$

\section{Background}

Anemia can be defined as a reduction in the hemoglobin, hematocrit, or red cells number. In physiologic terms, anemia is any disorder in which the patient suffers from tissue hypoxia due to decreased oxygen carrying capacity of the blood [1]. It is mainly caused by iron deficiency in all developing countries, including Africa, where consumption of iron is limited. This is because iron-rich or animal based foods are not affordable by most families. Children $<2$ years and pregnant women are most at risk for anemia because their requirements for iron are higher than any other group [2].

The World Health Organization (WHO) considers anemia prevalence over $40 \%$ as a major public health problem, between $20 \%$ and $40 \%$ as a medium level public health problem, and between $5 \%$ and $20 \%$ as a mild public health problem [3]. High prevalence of anemia and its consequences on children's health, especially for their growth and development, have made anemia an important public health problem, given the difficulty in implementing effective measures for controlling it. Severe anemia (hemoglobin $<7 \mathrm{~g} / \mathrm{dL}$ ) is a public health problem if prevalence exceeds $2 \%[4]$

According the 2004 WHO report, more than 2 billion people worldwide are anemic and about $47.4 \%$ of preschool children are affected by the problem. It affects most of countries in Africa and South Asia and some countries in East Asia and the Pacific. The highest prevalence of anemia is in Africa, but the greatest numbers of children affected are found in Asia [5]

In developing countries, it is reported that an estimated 3.5 billion people are anemic. The 2008 WHO estimate of anemia prevalence in Africa was $64.6 \%$, which is almost 50 percentage points higher than the prevalence in Europe (16.4\%), and over 60 percentage points higher than in North America (3.4\%). Anemia in children is of particular interest since it impairs their mental, physical and social development; it causes negative behavioral and cognitive effects resulting in poor school performance and work capacity in later years [6]. According to WHO 2015 report, about $43 \%$ of under-five children were anemic, with regional variations of $62.3 \%$ in Africa, 53.8\% in South-East Asia and 21.9\% in Western Pacific Region. Africa and Asia are found with sever public health importance of anemia.

Hospital-based, cross-sectional study in Tanzania conducted between November 2012 and February 2013 revealed that the prevalence of anaemia among under five children was $77.2 \%$ with mild, moderate and severe anaemia being $16.5 \%, 33 \%$ and $27.7 \%$ respectively. And unemployment of the parent, malaria parasitaemia and presence of sickle haemoglobin are associated with severe anaemia [7]. Prevalence rate of anemia among underfives was inflated to $84.6 \%$ by 2018 and low birth weight and dietary factors (ie, low or no consumption of ironrich foods like meat, vegetables, and fruits) were predictors of anemia among under-five children living in the rural Tanzania [8].

According to EDHS 2011 report, a number of interventions have been put in place in Ethiopia to address the high prevalence of anaemia in children. More than four in ten Ethiopian children (44\%) are anaemic. One child of every five (21\%) has mild anaemia, another $20 \%$ have moderate anaemia, and $3 \%$ have severe anaemia. Anaemia prevalence is highest among children age $9-11$ months (73\%) and decreases steadily with age from 12 to 59 months. 
Forty-five percent of children in rural areas have anaemia, compared with 35 percent of children in urban areas. Regional variation of anaemia in children ranges from 33\% in Addis Ababa to $75 \%$ in Affar. Anaemia among children decreases with increases in mother's education and wealth quintile. The national anaemia prevalence estimate has dropped by $19 \%$, from $54 \%$ in 2005 to $44 \%$ in 2011 . This change is due largely to the drop in the prevalence of moderate anaemia; estimates of the prevalence of mild and severe anaemia have remained stable. The prevalence of moderate anaemia decreased from $28 \%$ in 2005 to $20 \%$ in 2011 [9].

Community based cross-sectional study conducted in 2014 in Kilte Awulaelo Woreda; Northern Ethiopia showed that the prevalence of anemia among children aged 6-59 months was a moderate public health problem with $37.3 \%$ according to WHO classification. This research revealed that Children who were aged 6-23 months, underweight, having MUAC less than $12 \mathrm{~cm}$, from households with annual income below 10,000 Ethiopian birr were more likely to become anemic [10].

The prevalence of anaemia was $28.2 \%$ in 2014 and increased to $36.8 \%$ in 2015 . The incidence of anaemia was 30 cases per 100 children years of observation. The risk of anaemia was high among children with malaria. Children from poor families stunted children, and children aged less than 36 months were at risk of anaemia compared to their counterparts. There was no significant difference in risk of Anaemia among the trial arms [11]. This study aimed to determine the prevalence of mild, moderate and severe anaemia, and the associated factors among children under-five years in Ethiopia.

\section{Methods \\ Source of Data and Study Design}

The data was obtained from 2016 EDHS, which was taken from Central Statistical Agency (CSA). It is the fourth survey conducted in Ethiopia as part of the worldwide project. The 2016 EDHS sample was stratified and selected in two stages. Each region was stratified into urban and rural areas, yielding 21 sampling strata. Samples of Enumeration Areas (EAs) were selected independently in each stratum in two stages. Implicit stratification and proportional allocation were achieved at each of the lower administrative levels by sorting the sampling frame within each sampling stratum before sample selection, according to administrative units in different levels, and by using a probability proportional to size selection at the first stage of sampling. In this study a total of 4,684 underfive children affected by anaemia were considered from nine regional states and two city administratives [12].

\section{Outcome variable}

The outcome variable in this study was the level of anemia among children which is classified based on hemoglobin concentration and categorized as follows.

$$
\text { Level of anaemia }=\left\{\begin{array}{l}
\text { mild, if } 10 \mathrm{~g} / \mathrm{dl}-10.9 \mathrm{~g} / \mathrm{dl} \\
\text { moderate, if } 7 \mathrm{~g} / \mathrm{dl}-9.9 \mathrm{~g} / \mathrm{dl} \\
\text { Severe, if less than } 7 \mathrm{~g} / \mathrm{dl}
\end{array}\right.
$$

\section{Method of Data Analysis}

Based on the valid data obtained, we have performed a descriptive analysis using frequency distribution, percentage and chi-square test of association. To identify risk factors of anaemia amongst Ethiopian children Partial Proportional Odds model (PPOM) was used. PPOM can be used when parallel lines assumption holds or not. The maximum likelihood estimation technique was applied to estimate parameters of the model [13]. Data cleaning, management and analysis were carried out using STATA, Version 12. Variables were re-coded to meet the desired classification. All hypotheses testing to determine differences, associations and relationships were judged significant at $\mathrm{p}<0.05$

\section{Result}

In this study a total of 4,684 under-five children affected by anemia were considered from nine regional states and two city administrative. The result in table 1 revealed that more than half of the children (54\%) are at moderate while $39.4 \%$ and $6.6 \%$ of them are at mild and severe anemic status respectively.

The size of each level of anaemia by different socio-demographic factors with their corresponding chi-square test of association had been presented in table 1 . More than half of the children $(51.9 \%)$ were female and the remaining $48.1 \%$ are male. The result also showed that about $55.1 \%$ of female children are moderately anaemic while $36.6 \%$ and $6.7 \%$ of them are at mild and severe anaemic status respectively. Among male children about $40.6 \%, 52.8 \%$ and $6.6 \%$ of them are mild, moderate and severe anaemic status respectively. Majority of the anaemia prevalence $(84.6 \%$ ) was from rural part of Ethiopia of which $54.4 \%$ and $7.1 \%$ were moderate and severe anaemic status respectively. According to age of the child, the highest percentage $(27 \%)$ and the smallest percentage (15.2\%) were 12-23 months and 6-11 months respectively. About 9\% of 24-35 months of age children are at severe anaemic status while $61.3 \%$ of $12-23$ months old child were at moderate level. About $52 \%$ of mild anaemia is observed among 48-59 months old children. 
More than half of anaemic children $(60.2 \%)$ were from poor families while $13 \%$ and $26.8 \%$ of anaemic children were from middle and rich families. About 35.4\%, 56\% and 8.6\% of anaemic children from poor families were at mild, moderate and severe anaemic status respectively. According to regional states of the country, the highest severe anaemia is found in Somalia region which is estimated to be $14.5 \%$ followed by Dire Dawa and Harari with $14.2 \%$ and $7.3 \%$ respectively. In addition, $5.9 \%, 5.1 \%$ and $4.8 \%$ of anaemic children from Afar, Oromia and Amhara are at severe anaemic level respectively.

The association between predictor variables and anemia status of children was identified by conducting chisquare test of association from table 1 we conclude that there is association between wealth index, region, breast mother education and residence with prevalence anemia among children in Ethiopia.

\section{Linear Trend Alternative to Independence for Some Selected Variables}

By using equal space score method, from table 2 the result implied that there is a linear dependence between mother education and status of anemia at $5 \%$ significance level since p-value $(0.038<0.05)$ similarly, there is a linear dependence between residence, weight and status of anemia since p-value $(0.001<0.05)$.

\section{Results of PPOM}

Parallel-lines assumption for each variable was tested using a series of Wald tests to see whether its coefficients differ across equations. Since the parallel-lines assumption has been violated by some of explanatory variable ordinal logistic regression cannot be used. Therefore, PPOM was used and the result was showed in table 3 below. The coefficients for wealth index are consistently negative but decline across cut-points. This means that children were their wealth index was poor more affected by anemia than the children's whose their wealth index were middle and rich, with the greatest differences being the children poor were less likely to put themselves in moderate and severe categories. Conversely, the age group effect is negative but gets larger across cut points. Hence, higher age group tend to be less anemic than lower age group with the greatest differences being that higher age group are less likely to place in put themselves moderate and severe categories.

Sex, the odds of having higher chance of moderate and severe anemia for male children is $14 \%$ less likely than female children when it is compared with Mild anemia. Likewise, the odds of having higher chance of severe anemia for male children 14\% less likely than female children when it is compared with Mild and moderate anemia.

Residence, we would say that for residence going from urban to rural the odds of severe anemia versus the combined moderate and mild anemia categories are 1.473 greater, given that all of the other variables in the model are held constant. Likewise, the odds of the combined moderate and severe anemia versus mild anemia are 1.473 times greater, given that all of the other variables in the model are held constant, indicate that severity of anemia is in rural than in urban area.

Regions, when the region of children are Afar, Oromia, Somali, Harari and Addis Ababa, the odds of mild anemia versus the combined moderate and severe anemia categories are 1.37, 1.39, 3.963, 2.11 and 2.011 greater respectively, given that all of the other variables in the model are held constant respectively, indicate that in those region the prevalence of anemia is high, but for Benishangul-Gumuz odds of mild anemia versus the combined moderate and severe anemia is 0.638 less likely Tigray region, given that all of the other variables in the model are held constant, indicate that the prevalence of anemia is low. However, for Dire Dawa, the odd of moderate and severe anemia versus mild anemia is twice of the odds of mild anemia versus the combined moderate and severe anemia given that all of the other variables in the model are held constant.

\section{Discussion}

In this study, we were attempts to investigate the prevalence of anemia in Ethiopia and identify the associated factors of children aged under-five. The prevalence of anemia in Ethiopia was found to be (54\%) are at moderate while $39.4 \%$ and $6.6 \%$ of them are at mild and severe anemic status respectively. The prevalence of anemia in Ethiopia is high when we compared with finding conducted in Togo of which $42.7 \%$ had moderate, $25.6 \%$ had mild anemia, anemia and $2.6 \%$ had severe anemia [14].

Higher age group tends to be less anemic than Lower age group in line with the findings done in Kenya and West Africa [15-17]. On the other hand, our findings show that children with lower age groups had a higher chance of severing anemic and the result is consistent with the previous study conducted in some countries like Nepal, rural India and Brazil [18-21]. This is might be due to the Hemoglobin concentration had undeviating and a progressive association with age. The reason behind this could be the fact that as age get increased; an insistent dietary nutrient for growth relatively becomes lower than an early age.

Regarding Weight of children, the PPOM shows that as Weight of children is increased the odds of Mild anemia vs moderate and severe anemia, as well as the odds Mild and moderate anemia vs severe anemia is $1 \%$ less likely times. This finding was agreed with studies conducted in Punjab India, Tanzania, Kenya and Nigeria [2226]. In case this may be due to Undernourishment and insufficient dietary maybe leads to iron deficiency which is one of the major associated factors of anemia [27-29]. 
The study revealed that children whose theirs residence is rural are more likely affected by anemia compared to the children whose theirs residence is urban by the prevalence of anemia that consistent with other studies [6, 30]. They indicated that better access to food and quality diet in urban, better access to medical care.

Our study also revealed that the chance of having severe anemia status was found to decrease with the increase of household wealth index, or under-five children from poor households are at a higher risk of prevalence of anemia than children from rich households. This finding is consistent with other studies [30]. They indicated that better access to food and higher cash incomes than poor households, allowing them quality diet, better access to medical care and more money to spend on essential nonfood items such as schooling, clothing and hygiene products.

\section{Conclusion}

From 4684 sample of children half of the children (54\%) have moderate anemic status while $39.4 \%$ and $6.6 \%$ of them have mild and severe anemic status respectively. The highest prevalence of anemia among children observed in Somali (17.8\%) and the lowest percentage that was recorded in Addis Ababa (3.1\%). Emphasis should be given for female children, rural children, children from poor family, and children having low weight.

\section{List of abbreviations}

CSA: Central Statistical Agency

EAs: $\quad$ Enumeration Areas

EDHS: Ethiopian Demographic and Health Survey

OR: $\quad$ Odds Ratio

PPOM: Partial Proportional Odds Model

WHO: World Health Organization

\section{Declarations}

Ethics approval and consent to participate

Ethics approval and participant consent were not necessary as this study involved the use of a previously-published database by CSA of Ethiopia.

\section{Consent for publication}

Not applicable

\section{Availability of data and material}

The dataset was demanded and retrieved from CSA website after formal online registration and submission of the project title and detail project description

\section{Competing interests}

The authors declare that they have no competing interests

\section{Authors' contributions}

All authors contribute equally for this research.

\section{Funding}

Not applicable

\section{Acknowledgements}

The authors are grateful to CSA of Ethiopia for the data used in this study.

\section{Reference}

1. World Health Organization. (2015). Global technical strategy for malaria 2016-2030. World Health Organization.World Bank (2004), Poverty and Income, the Poverty Group. http://devdata.worldbank.org/hnpstats/pvd.asp.

2. World Health Organization. (2001). Iron deficiency anemia. assessment, prevention, and control. A guide for programme managers, 47-62..

3. Stoltzfus, R. J. (2001). Defining iron-deficiency anemia in public health terms: a time for reflection. The Journal of nutrition, 131(2), 565S-567S.

4. McLean, E., Cogswell, M., Egli, I., Wojdyla, D., \& De Benoist, B. (2009). Worldwide prevalence of anaemia, WHO vitamin and mineral nutrition information system, 1993-2005. Public health nutrition, 12(4), 444-454.

5. Ewusie, J. E., Ahiadeke, C., Beyene, J., \& Hamid, J. S. (2014). Prevalence of anemia among under-5 children 
in the Ghanaian population: estimates from the Ghana demographic and health survey. BMC public health, $14(1), 626$.

6. Simbauranga, R. H., Kamugisha, E., Hokororo, A., Kidenya, B. R., \& Makani, J. (2015). Prevalence and factors associated with severe anaemia amongst under-five children hospitalized at Bugando Medical Centre, Mwanza, Tanzania. BMC hematology, 15(1), 13.

7. Kejo, D., Petrucka, P. M., Martin, H., Kimanya, M. E., \& Mosha, T. C. (2018). Prevalence and predictors of anemia among children under 5 years of age in Arusha District, Tanzania. Pediatric health, medicine and therapeutics, 9, 9 .

8. Central Statistical Agency [Ethiopia] and ICF International. (2012). Ethiopia Demographic and Health Survey 2011,Central StatisticalAgency, Addis Ababa, Ethiopia; ORC Macro, Calverton, Md, USA

9. Gebreegziabiher, G., Etana, B., \& Niggusie, D. (2014). Determinants of anemia among children aged 6-59 months living in Kilte Awulaelo Woreda, northern Ethiopia. Anemia, 2014.

10. Gari, T., Loha, E., Deressa, W., Solomon, T., Atsbeha, H., Assegid, M., ... \& Lindtjørn, B. (2017). Anaemia among children in a drought affected community in south-central Ethiopia. PloS one, 12(3), e0170898

11. Central Statistical Agency (CSA) Ethiopia and ICF (2016): Demographic and Health Survey 2016: Key Indicators Report. In. Addis Ababa, Ethiopia and ICF Rockville, Maryland, USA. CSA and ICF

12. Agresti, A. (2018). An introduction to categorical data analysis. Wiley.

13. Nambiema, A., Robert, A., \& Yaya, I. (2019). Prevalence and risk factors of anemia in children aged from 6 to 59 months in Togo: analysis from Togo demographic and health survey data, 2013-2014. BMC public health, 19(1), 215.

14. Ngesa, O., \& Mwambi, H. (2014). Prevalence and risk factors of anaemia among children aged between 6 months and 14 years in Kenya. PLoS One, 9(11), e113756.

15. Magalhaes, R. J. S., \& Clements, A. C. (2011). Mapping the risk of anaemia in preschool-age children: the contribution of malnutrition, malaria, and helminth infections in West Africa. PLoS medicine, 8(6), e1000438.

16. Muchie, K. F. (2016). Determinants of severity levels of anemia among children aged 6-59 months in Ethiopia: further analysis of the 2011 Ethiopian demographic and health survey. BMC Nutrition, 2(1), 51.

17. Khanal, V., Karkee, R., Adhikari, M., \& Gavidia, T. (2016). Moderate-to-severe anaemia among children aged 6-59 months in Nepal: an analysis from Nepal demographic and health survey, 2011. Clinical epidemiology and global health, 4(2), 57-62.

18. Agho, K. E., Dibley, M. J., D'Este, C., \& Gibberd, R. (2008). Factors associated with haemoglobin concentration among Timor-Leste children aged 6-59 months. Journal of health, population, and nutrition, 26(2), 200

19. Pasricha, S. R., Black, J., Muthayya, S., Shet, A., Bhat, V., Nagaraj, S., ... \& Shet, A. S. (2010). Determinants of anemia among young children in rural India. Pediatrics, 126(1), e140-e149.

20. Leite, M. S., Cardoso, A. M., Coimbra, C. E., Welch, J. R., Gugelmin, S. A., Lira, P. C. I., ... \& Escobar, A. L. (2013). Prevalence of anemia and associated factors among indigenous children in Brazil: results from the First National Survey of Indigenous People's Health and Nutrition. Nutrition journal, 12(1), 69.

21. Gupta, V. K., Maria, A. K., Kumar, R., Bahia, J. S., Arora, S., Singh, R., \& Gupta, V. (2011). To study the prevalence of anaemia in young males and females with respect to the age, body mass index (BMI), activity profile and the socioeconomic status in rural Punjab. Journal of Clinical and Diagnostic Research, 5(5), 102026.

22. Tatala, S. R., Kihamia, C. M., Kyungu, L. H., \& Svanbergrhaaa, U. (2008). Risk factors for anaemia in schoolchildren in Tanga Region, Tanzania. Tanzania journal of health research, 10(4).

23. Pullan, R. L., Gitonga, C., Mwandawiro, C., Snow, R. W., \& Brooker, S. J. (2013). Estimating the relative contribution of parasitic infections and nutrition for anaemia among school-aged children in Kenya: a subnational geostatistical analysis. BMJ open, 3(2), e001936.

24. Leenstra, T., Kariuki, S. K., Kurtis, J. D., Oloo, A. J., Kager, P. A., \& ter Kuile, F. O. (2004). Prevalence and severity of anemia and iron deficiency: cross-sectional studies in adolescent schoolgirls in western Kenya. European journal of clinical nutrition, 58(4), 681

25. Onimawo, I. A., Ukegbu, P. O., Asumugha, V. U., Anyika, J. U., Okudu, H., Echendu, C. A., ... \& Emebu, P. (2010). Assessment of anaemia and iron status of school age children (aged 7-12 years) in rural communities of Abia state, Nigeria. African Journal of Food, Agriculture, Nutrition and Development, 10(5).

26. van den Broek, N. R., \& Letsky, E. A. (2000). Etiology of anemia in pregnancy in south Malawi. The American journal of clinical nutrition, 72(1), 247S-256S.

27. Black, R. E., Morris, S. S., \& Bryce, J. (2003). Where and why are 10 million children dying every year?. The lancet, 361(9376), 2226-2234

28. Halterman, J. S., Kaczorowski, J. M., Aligne, C. A., Auinger, P., \& Szilagyi, P. G. (2001). Iron deficiency and cognitive achievement among school-aged children and adolescents in the United States. Pediatrics-English Edition, 107(6), 1381-1386. 
29. Kawo, K. N., Asfaw, Z. G., \& Yohannes, N. (2018). Multilevel Analysis of Determinants of Anemia Prevalence among Children Aged 6-59 Months in Ethiopia: Classical and Bayesian Approaches. Anemia, 2018.

Table 1 Basic covariates of Anaemia status among children

\begin{tabular}{|c|c|c|c|c|c|c|}
\hline \multirow{2}{*}{ Variable } & \multirow{2}{*}{ Category } & \multirow{2}{*}{ Total (\%) } & \multicolumn{3}{|c|}{ Anaemia status } & \multirow{2}{*}{ P-value } \\
\hline & & & Mild (\%) & Moderate $(\%)$ & Severe $(\%)$ & \\
\hline \multicolumn{7}{|c|}{ Breast Feeding } \\
\hline & Ever/not current & $2517(53.7)$ & $1043(41.4)$ & $1286(51.1)$ & $188(7.5)$ & \multirow[t]{3}{*}{$0.000 *$} \\
\hline & Never & $178(3.8)$ & $73(41.1)$ & $93(52.2)$ & $12(6.7)$ & \\
\hline & Still & $1989(42.5)$ & $728(36.6)$ & $1151(57.9)$ & $110(5.5)$ & \\
\hline \multicolumn{7}{|l|}{ Sex } \\
\hline & Female & $2430(51.9)$ & $928(38.2)$ & $1340(55.1)$ & $162(6.7)$ & \multirow[t]{2}{*}{$0.024 *$} \\
\hline & Male & $2254(48.1)$ & $916(40.6)$ & $1190(52.8)$ & $148(6.6)$ & \\
\hline \multicolumn{7}{|l|}{ Residence } \\
\hline & Urban & $719(15.4)$ & $316(43.9)$ & $373(51.9)$ & $30(4.2)$ & \multirow[t]{2}{*}{$0.002 *$} \\
\hline & Rural & $3965(84.6)$ & $1528(38.5)$ & $2157(54.4)$ & $280(7.1)$ & \\
\hline \multicolumn{7}{|l|}{ Age group } \\
\hline & $6-11$ & $714(15.2)$ & $257(36)$ & $421(59)$ & $36(5)$ & \multirow{5}{*}{$0.000 *$} \\
\hline & $12-23$ & $1266(27)$ & $409(32.3)$ & $776(61.3)$ & $81(6.4)$ & \\
\hline & $24-35$ & $1054(22.5)$ & $399(37.9)$ & $560(53.1)$ & $95(9)$ & \\
\hline & $36-47$ & $885(18.9)$ & $381(43.0)$ & $445(50.3)$ & $59(6.7)$ & \\
\hline & $48-59$ & $765(16.3)$ & $398(52.0)$ & $328(42.9)$ & $39(5.1)$ & \\
\hline \multicolumn{7}{|c|}{ Wealth index } \\
\hline & Poor & $2821(60.2)$ & 999 (35.4) & $1580(56)$ & $242(8.6)$ & \multirow{3}{*}{$0.000 *$} \\
\hline & Middle & $610(13.0)$ & $278(45.6)$ & $307(50.3)$ & $25(4.1)$ & \\
\hline & Rich & $1253(26.8)$ & $567(45.3)$ & $643(51.3)$ & $43(3.4)$ & \\
\hline \multicolumn{7}{|l|}{ Regions } \\
\hline & Tigray & $440(9.4)$ & $210(47.7)$ & $215(48.9)$ & $15(3.4)$ & \multirow{11}{*}{$0.000 *$} \\
\hline & Afar & $561(12.0)$ & $204(36.4)$ & $324(57.8)$ & $33(5.9)$ & \\
\hline & Amhara & $331(7.1)$ & $178(53.8)$ & $137(41.4)$ & $16(4.8)$ & \\
\hline & Oromia & $784(16.7)$ & $323(41.2)$ & $421(53.7)$ & $40(5.1)$ & \\
\hline & Somali & $833(17.8)$ & $175(21)$ & $537(64.5)$ & $121(14.5)$ & \\
\hline & SNNP & $504(10.8)$ & $252(50)$ & $238(47.2)$ & $14(2.8)$ & \\
\hline & Benishangul & $280 \quad(6.0)$ & $156 \quad(55.7)$ & $119(42.5)$ & $5(1.8)$ & \\
\hline & Gumuz Gambela & $297(6.3)$ & $117(39.4)$ & $175(58.9)$ & $5(1.7)$ & \\
\hline & Harari & $248(5.3)$ & $87(35.1)$ & $143(57.7)$ & $18(7.3)$ & \\
\hline & Addis Ababa & $146(3.1)$ & $60(41.1)$ & $80(54.8)$ & $6(4.1)$ & \\
\hline & Dire Dawa & $260(5.6)$ & $82(31.5)$ & $141(54.3)$ & $37(14.2)$ & \\
\hline \multicolumn{7}{|c|}{ Mother Education } \\
\hline & no educated & $2793(59.6)$ & $1118(40.0)$ & $1486(53.2)$ & $189(6.8)$ & \multirow{4}{*}{0.005} \\
\hline & Primary & $1164(24.8)$ & $457(39.3)$ & $630(54.1)$ & $77(6.6)$ & \\
\hline & Secondary & $368(7.9)$ & $123(33.4)$ & $214(58.2)$ & $31(8.4)$ & \\
\hline & college and above & $359(7.7)$ & $146(40.7)$ & $200(55.7)$ & $13(3.6)$ & \\
\hline Total & & $4684(100)$ & $1844(39.4$ & 2530.0 & 310.6 & \\
\hline
\end{tabular}

$\underline{\text { Table } 2}$ Trend Alternative to Independence for some selected variables

\begin{tabular}{cllllll}
\hline variable & Status of anemia & score & Observation & sum of ranks & Z-score & Prob $>|\mathbf{z}|$ \\
\hline Mother & Mild & 1 & 1741 & 3802731.5 & 2.08 & 0.038 \\
Education & Moderate & 2 & 2411 & 5444580.5 & & \\
& Severe & 3 & 307 & 696258 & & 0.001 \\
Residence & Mild & 1 & 1844 & 4242416 & 3.45 & \\
& Moderate & 2 & 2530 & 5962494 & & 0.000 \\
& Severe & 3 & 310 & 767360 & & -9.66 \\
Weight & Mild & 1 & 1844 & 4754710.5 & & \\
\hline
\end{tabular}


Table 3 Results of PPOM

\begin{tabular}{|c|c|c|c|c|c|c|c|}
\hline \multirow[b]{2}{*}{ Variable } & \multirow[b]{2}{*}{ category } & \multicolumn{3}{|c|}{ Mild vs moderate and severe anemia } & \multicolumn{3}{|c|}{ Mild and moderate vs severe anemia } \\
\hline & & $\mathrm{B}_{1}$ & $\mathrm{OR}_{1}$ & p-value & $\mathrm{B}_{2}$ & $\mathrm{OR}_{2}$ & p-value \\
\hline Intercept & & 0.83 & 2.29 & $0.001 *$ & -1.56 & 0.21 & $0.000^{*}$ \\
\hline \multirow[t]{2}{*}{ Sex } & Female & Ref. & & & & & \\
\hline & Male & -0.15 & 0.86 & $0.014 *$ & -0.15 & 0.86 & $0.014^{*}$ \\
\hline \multirow[t]{2}{*}{ Residence } & Urban & Ref. & & & & & \\
\hline & Rural & 0.39 & 1.47 & $0.001 *$ & 0.39 & 1.47 & $0.001 *$ \\
\hline Wealth & Poor & Ref. & & & & & \\
\hline \multirow[t]{2}{*}{ Index } & Middle & -0.27 & 0.77 & $0.005 *$ & -0.27 & 0.77 & $0.005^{*}$ \\
\hline & Rich & -0.18 & 0.83 & $0.049 *$ & -0.18 & 0.83 & $0.049 *$ \\
\hline \multirow[t]{11}{*}{ Regions } & Tigray & Ref. & & & & & \\
\hline & Afar & 0.31 & 1.37 & $0.017 *$ & 0.31 & 1.37 & $0.017^{*}$ \\
\hline & Amhara & -0.19 & 0.83 & 0.201 & -0.19 & 0.83 & 0.201 \\
\hline & Oromia & 0.33 & 1.39 & $0.007 *$ & 0.33 & 1.39 & $0.007 *$ \\
\hline & Somali & 1.38 & 3.961 & $0.000 *$ & 1.38 & 3.96 & $0.000^{*}$ \\
\hline & Ben-Guz & -0.45 & 0.64 & $0.004 *$ & -0.45 & 0.64 & $0.004 *$ \\
\hline & SNNP & -0.03 & 0.97 & 0.836 & -0.03 & 0.97 & 0.836 \\
\hline & Gambella & 0.414 & 1.50 & $0.012 *$ & -0.81 & 0.45 & 0.084 \\
\hline & Harari & 0.75 & 2.11 & $0.000 *$ & 0.75 & 2.11 & $0.000 *$ \\
\hline & Addis Ababa & 0.70 & 2.01 & $0.007 *$ & 0.70 & 2.01 & 0.07 \\
\hline & Dire Dawa & 0.86 & 2.37 & $0.000 *$ & 1.46 & 4.32 & $0.000 *$ \\
\hline \multicolumn{2}{|l|}{ Weight } & -0.01 & 0.99 & $0.000 *$ & -0.03 & 0.98 & $0.000 *$ \\
\hline \multirow[t]{5}{*}{ Age group } & $6-11$ & Ref. & & & & & \\
\hline & $12-23$ & 0.33 & 1.40 & $0.001 *$ & 0.33 & 1.40 & $0.001 *$ \\
\hline & $24-35$ & 0.14 & 1.15 & 0.278 & 1.05 & 2.86 & $0.000^{*}$ \\
\hline & $36-47$ & 0.04 & 1.05 & 0.779 & 1.05 & 2.85 & $0.000^{*}$ \\
\hline & $48-59$ & -0.18 & 0.84 & 0.311 & 1.13 & 3.11 & $0.000^{*}$ \\
\hline
\end{tabular}

